EXTENDED REPORT

\title{
Serum concentrations of soluble P-selectin glycoprotein ligand-1 are increased in patients with systemic sclerosis: association with lower frequency of pulmonary fibrosis
}

\author{
K Yanaba, K Takehara, S Sato
}

Ann Rheum Dis 2004;63:583-587. doi: 10.1136/ard.2003.011122

See end of article for authors' affiliations

Correspondence to: Dr Shinichi Sato,

Department of Dermatology, Kanazawa University Graduate School of Medical Science, 13-1 Takaramachi, Kanazawa, Ishikawa 9208641, Japan; s-sato@ med.kanazawa-u.ac.jp

Accepted 14 July 2003

\begin{abstract}
Objective: To determine serum concentrations of soluble P-selectin glycoprotein ligand-1 (sPSGL-1) and its clinical associations in patients with systemic sclerosis.

Methods: Serum sPSGL-1 concentrations from 65 patients with systemic sclerosis were examined by enzyme linked immunosorbent assay. In a retrospective longitudinal study, 177 sera from 35 patients with systemic sclerosis were analysed (follow up 0.3 to 6.3 years)

Results: Serum sPSGL-1 was raised in patients with limited cutaneous systemic sclerosis (ISSc) $(n=34)$ and diffuse cutaneous systemic sclerosis (dSSc) $(n=31)$ compared with healthy controls $(n=22)$ and patients with systemic lupus erythematosus $(n=20)$ or dermatomyositis $(n=20)$. Patients with systemic sclerosis who had raised sPSGL-1 concentrations less often had pulmonary fibrosis and decreased vital capacity (\%VC) than those with normal sPSGL-1 levels. sPSGL-1 concentrations were positively correlated with \%VC in patients with systemic sclerosis. In the longitudinal study, patients with systemic sclerosis but without pulmonary fibrosis had consistently increased SPSGL-1 concentrations in the early phase, while those with pulmonary fibrosis had decreased sPSGL-1 throughout the follow up period.

Conclusions: A raised serum SPSGL-1 is associated with a lower frequency and severity of pulmonary fibrosis in systemic sclerosis. SPSGL-1 could be a protective factor against the development of pulmonary fibrosis in this disease and as such would be a possible therapeutic target.
\end{abstract}

S ystemic sclerosis is a generalised connective tissue disorder characterised by sclerotic changes in the skin and internal organs. It is generally regarded as an autoimmune disorder because of the presence of antinuclear antibodies. Although the pathogenesis of the disease remains unclear, previous studies have suggested that cytokines or growth factors regulate the induction of systemic sclerosis by stimulating the synthesis of extracellular matrix components, injuring endothelial cells, and modulating the function of leucocytes. ${ }^{12}$ These cytokines or growth factors are produced by inflammatory cells infiltrating the affected tissues-such as the skin or lungs - of patients with systemic sclerosis. ${ }^{1-3}$

Leucocyte recruitment from the circulation into a site of inflammation is a multistep process that is regulated by multiple cell surface adhesion molecules. ${ }^{45}$ Leucocytes first tether and roll on vascular endothelial cells, before they are activated to adhere firmly and subsequently to emigrate into the extravascular space. The selectins primarily mediate tethering and rolling of leucocytes. ${ }^{4}{ }^{6}$ The selectin family consists of three cell surface molecules expressed by leucocytes (L-selectin), vascular endothelium (E- and Pselectin), and platelets (P-selectin). ${ }^{7}$ While P-selectin is rapidly mobilised to the surface of activated endothelium or platelets, E-selectin expression is induced within several hours after activation with inflammatory cytokines. ${ }^{7}$ Lselectin is constitutively expressed on most leucocytes. ${ }^{7}$ Sialyl-Lewis $\mathrm{X}$ and other fucosylated carbohydrates have been identified as counter-receptors for the selectins. ${ }^{8}$ One such molecule is P-selectin glycoprotein ligand-1 (PSGL-1), a high affinity ligand for P-selectin found on most leucocytes. ${ }^{9}$ PSGL- 1 has also been shown to bind E- and L-selectin, but their affinities are lower than that of P-selectin. ${ }^{10-14}$

In addition to membrane bound PSGL-1, a soluble form of PSGL-1 (sPSGL-1) has been identified. ${ }^{10}$ Soluble forms of adhesion molecules have been shown to retain their function and hence can compete with membrane bound adhesion molecules, acting to inhibit adhesion. ${ }^{15}$ sPSGL-1 has been shown to be capable of binding $\mathrm{P}_{-}, \mathrm{E}-$, and L-selectin and act as an antagonist of PSGL-1. ${ }^{12} 1617$

In this study, we examined serum concentrations of sPSGL-1 in patients with systemic sclerosis, and related the results to their clinical features. In addition, we undertook a retrospective longitudinal study of SPSGL-1 concentrations in some of these patients to determine the changes in SPSGL-1 over time.

\section{METHODS}

\section{Patients}

Serum samples were obtained from 65 Japanese patients with systemic sclerosis (57 female and eight male). All patients fulfilled the criteria for systemic sclerosis proposed by the American College of Rheumatology (ACR). ${ }^{18}$ According to the classification system proposed by LeRoy et al, ${ }^{19} 34$ patients had limited cutaneous systemic sclerosis (ISSc) and 31 had diffuse cutaneous systemic sclerosis (dSSc). Antitopoisomerase I (Topo I) antibodies were positive in 28 patients; anticentromere antibodies in 21; anti-RNA polymerase I antibodies in three; anti-Ul RNP antibodies in six; anti-U3 RNP antibodies in two; anti-Th/To antibodies in three; and two were negative. The patients were aged 2 to 72 years (mean age 45). The mean disease duration was 5.4 years (range 0.2 to 30 ). The duration of the disease was calculated from the time of onset of the first clinical event

Abbreviations: dSSc, diffuse cutaneous systemic sclerosis; HRCT, high resolution computed tomography; ISSc, limited cutaneous systemic sclerosis; sPSGL-1, soluble P-selectin glycoprotein ligand-1 
(other than Raynaud's phenomenon) that was a clear manifestation of systemic sclerosis.

At their first visit, nine patients had been treated with low dose steroids (prednisolone 5 to $20 \mathrm{mg}$ /day) and eight with low dose D-penicillamine ( 100 to $500 \mathrm{mg}$ /day). None of the patients had received immunosuppressive treatment.

Twenty patients with systemic lupus erythematosus (SLE) who fulfilled the ACR criteria ${ }^{20}$ and 20 with dermatomyositis who fulfilled the criteria of Bohan and Peter ${ }^{21}$ acted as disease controls; 22 healthy age and sex matched Japanese subjects acted as healthy controls.

In a retrospective longitudinal study, we analysed 177 serum samples from 35 of 65 patients with systemic sclerosis who could have been followed longitudinally. There was no bias in patient selection. The mean follow up period was 3.3 years (range 0.3 to 6.3 ), with 5.1 ( 2 to 9 ) time points. The mean disease duration was 5.4 years (range 0.2 to 22.8). Fifteen patients had ISSc and 20 had dSSc. Anti-topo I antibodies were positive in 23 patients; anticentromere antibodies in nine; anti-RNA polymerase I antibodies in two; and anti-Ul-RNP antibodies in one. These patients were aged 2 to 72 years (mean 49 ).

Fresh venous blood samples were centrifuged shortly after clot formation. All samples were stored at $-70^{\circ} \mathrm{C}$ before use.

\section{Clinical assessment}

Complete medical histories, physical examinations, and laboratory tests were conducted for all patients at their first visit, with evaluations especially for pulmonary function during follow up visits. Organ system involvement was defined as described ${ }^{22}{ }^{23}$-lung: bibasilar fibrosis on chest radiography and high resolution computed tomography (HRCT); oesophagus: hypomotility shown by barium radiography; joints: inflammatory polyarthralgia, tendon friction rubs, or acro-osteolysis; heart: pericarditis, congestive heart failure, or arrhythmias requiring treatment; kidney: malignant hypertension and rapidly progressive renal failure with no other explanation; and muscle: proximal muscle weakness and raised serum creatine kinase. Pulmonary fibrosis was defined as bibasilar interstitial fibrosis on chest radiographs, and ground glass opacities, reticular opacities, or honeycombing on HRCT. Each chest radiograph and HRCT was evaluated by a radiologist blinded to the patient's clinical status and serum findings, and independently by a second investigator.

Pulmonary function tests, including vital capacity (VC) and diffusion capacity for carbon monoxide (DLCo), were conducted to evaluate the severity of pulmonary fibrosis. When the DLco and VC were $<75 \%$ and $<80 \%$, respectively, of predicted normal values, they were considered to be abnormal. Patients with systemic sclerosis who were smokers or who had other respiratory disorders that could have affected \%DLco or \%VC were excluded from the study. The erythrocyte sedimentation rate was considered raised if it was more than $20 \mathrm{~mm} / \mathrm{h}, \mathrm{C}$ reactive protein if it was above $0.5 \mathrm{mg} /$ $\mathrm{dl}$, IgG if it was above $1774 \mathrm{mg} / \mathrm{dl}$, and IgM if it was above $355 \mathrm{mg} / \mathrm{dl}$.

The protocol was approved by the Kanazawa University Graduate School of Medicinal Science and Kanazawa University Hospital, and informed consent was obtained from all patients.

\section{Detection of serum sPSGL- 1}

Serum sPSGL-1 concentrations were measured using specific enzyme linked immunosorbent assay (ELISA) kits (Bender MedSystems, Vienna, Austria), according to the manufacturer's protocol. This ELISA system can detect all circulating sPSGL- 1 isoforms. Each sample was tested in duplicate. The detection limit of the assay was $1.5 \mathrm{U} / \mathrm{ml}$.

\section{Statistical analysis}

The Mann-Whitney U test was used to compare sPSGL-1 concentrations, Fisher's exact probability test to compare frequencies, and the Bonferroni test for multiple comparisons. Spearman's rank correlation coefficient was employed to examine the relation between two continuous variables. A probability (p) value of less than 0.05 was considered statistically significant.

\section{RESULTS}

\section{Serum sPSGL- 1 in systemic sclerosis}

Serum concentrations of SPSGL-1 in patients with systemic sclerosis and healthy controls are shown in fig 1 . For comparison, patients with dermatomyositis or SLE were also included in the study. Serum sPSGL-1 at the first visit was raised in patients with systemic sclerosis (median $18.1 \mathrm{U} / \mathrm{ml}$ (range 6.8 to 45.2$)$ ) compared with healthy controls (14.2 (9.5 to 17.6); $\mathrm{p}<0.05$ ), in patients with SLE (10.1 (6.7 to $16.5) ; \mathrm{p}<0.001)$, and in patients with dermatomyositis ( 13.0 (5.2 to 29.2); $\mathrm{p}<0.05$ ). Serum sPSGL-1 in patients with SLE was decreased compared with healthy controls $(p<0.0001)$. There was no significant difference in sPSGL-1 levels between patients with dermatomyositis and the healthy controls. In the systemic sclerosis subgroups, serum sPSGL-1 was $18.5 \mathrm{U} / \mathrm{ml}$ (6.8 to 45.2$)$ in patients with ISSc and 17.6 (8.5 to 36.9 ) in patients with dSSc; these values were significantly higher than in normal controls $(p<0.05$ for both), patients with SLE $(\mathrm{p}<0.005$ and $\mathrm{p}<0.0005$, respectively), or patients with dermatomyositis $(p<0.05$ and $\mathrm{p}<0.05)$. There was no significant difference in serum sPSGL-1 between patients with ISSc and dSSc.

\section{Clinical correlations of serum sPSGL-1}

Values higher than the mean +2 SD $(18.4 \mathrm{U} / \mathrm{ml})$ of the control serum samples were considered to be raised. Raised SPSGL- 1 concentrations were observed in $42 \%$ of patients with systemic sclerosis (27/65). As shown in table 1 , the prevalence of pulmonary sclerosis and decreased \%VC in patients with systemic sclerosis and raised SPSGL-1 values was significantly lower than in those with normal sPSGL-1

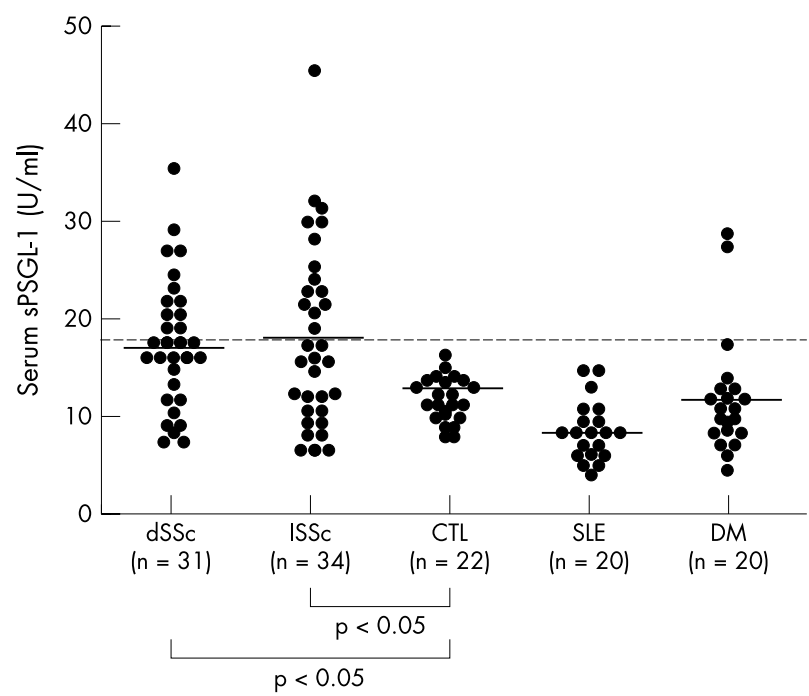

Figure 1 Serum concentrations of soluble P-selectin glycoprotein ligand-1 (sPSGL-1) in patients with diffuse cutaneous systemic sclerosis (dSSc), limited cutaneous systemic sclerosis (ISSc), systemic lupus erythematosus (SLE), dermatomyositis (DM), and normal controls (CTL). Serum sPSGL-1 concentrations were determined by a specific enzyme linked immunosorbent assay. Bars indicate the mean value in each group. The broken line indicates the cut off value (mean +2 SD of the normal control samples). 
Table 1 Clinical and laboratory data in patients with systemic sclerosis

\begin{tabular}{lll}
\hline & $\begin{array}{l}\text { Raised sPSGL- } \\
\text { (n=27) }\end{array}$ & $\begin{array}{l}\text { Normal sPSGL-1 } \\
\text { ( } \mathbf{n = 3 8 )}\end{array}$ \\
\hline $\begin{array}{ll}\text { Age at onset (years) (mean (SD)) } \\
\text { Male:female (n) }\end{array}$ & $\begin{array}{l}40(16) \\
1: 26\end{array}$ & $\begin{array}{l}49(11) \\
7: 31\end{array}$ \\
$\begin{array}{l}\text { Duration (years) (mean (SD) } \\
\text { Clinical features }\end{array}$ & $6.0(6.3)$ & $5.0(1.2)$ \\
Contracture of phalanges & 56 & \\
Pitting scars & 41 & 45 \\
Short sublingual frenulum & 56 & 42 \\
Organ involvement & & 55 \\
Lung & $15^{*}$ & 39 \\
Decreased \%VC & $15^{*}$ & 42 \\
Decreased \%Dlco & 44 & 66 \\
Oesophagus & 70 & 71 \\
Heart & 7 & 24 \\
Joint & 12 & 29 \\
Muscle & 19 & 11 \\
Laboratory findings & & 37 \\
Anti-topoisomerase I ab & 52 & 26 \\
Anticentromere ab & 37 & 47 \\
Increased lgG & $19^{*}$ & 32 \\
Raised ESR & 33 & 29 \\
Raised C reactive protein & 15 & \\
\hline
\end{tabular}

Values are percentages except where stated otherwise. ${ }^{*} \mathrm{p}<0.05 \vee$ patients with normal sPSGL- 1 .

ab, antibody; DLco, diffusion capacity for carbon monoxide; ESR, erythrocyte sedimentation rate; SPSGL-1, soluble P-selectin glycoprotein ligand-1; VC, vital capacity;

values $(15 \% \vee 39 \%, \mathrm{p}<0.05$, and $15 \% \vee 42 \%, \mathrm{p}<0.05$, respectively). sPSGL-1 concentrations were positively correlated with \%VC and \%DLco in patients with systemic sclerosis $(r=0.45, \mathrm{p}<0.005$, and $r=0.41, \mathrm{p}<0.01$, respectively; fig 2$)$. In addition, patients with a raised serum SPSGL- 1 less often had a raised serum IgG than those with a normal sPSGL-1 ( $19 \% \vee 47 \%, p<0.05$ ). Thus raised sPSGL-1 concentrations were associated with a lower frequency and severity of pulmonary sclerosis and an increased IgG.

\section{Longitudinal study of sPSGL-1 concentrations}

To assess changes in serum sPSGL-1 over time, 177 serum samples from 35 patients with systemic sclerosis were analysed retrospectively. The patients were divided into two groups: a group of 11 patients who had pulmonary sclerosis (fig 3A) and one of 24 patients who did not have pulmonary sclerosis (fig 3B).

In group A, two patients had already been treated with low dose steroids and one with low dose D-penicillamine at the time of their first visit. During the follow up period, low dose steroids (prednisolone, 5-20 mg/day) were started in five patients and low dose D-penicillamine (100-300 mg/day) in one. In addition, one patient received steroid pulse therapy, followed by $40 \mathrm{mg} /$ day of oral prednisolone, for subacute deterioration of pulmonary sclerosis.

In group B, two patients had already been treated with low dose steroids and two with low dose D-penicillamine (100$500 \mathrm{mg} /$ day) at the time of their first visit. During the follow up period, low dose steroids (prednisolone, 5-20 mg/day) were started in 10 patients and low dose D-penicillamine (100-500 mg/day) in three.

No patient with systemic sclerosis received immunosuppressive therapy. Among the 11 patients with pulmonary sclerosis (group A), two had raised serum sPSGL-1 at their first visit and their sPSGL-1 concentrations decreased to the normal range during the follow up period. In four of the patients in group A, sPSGL-1 concentrations increased only transiently during follow up. However, the maximum sPSGL1 values were relatively low $(<24 \mathrm{U} / \mathrm{ml})$ and they returned to normal levels in the late phase of disease process. In the remaining five patients in group A, sPSGL-1 concentrations remained normal throughout the follow up period.

Among the 24 patients without pulmonary sclerosis (group B), 17 had raised serum sPSGL- 1 concentrations at their first visit, and in eight of these the levels remained high throughout the follow up period. The maximum serum sPSGL-1 was comparatively high (>30 U/ml in five patients). Only four patients in this group had normal sPSGL-1 concentrations throughout the follow up.

In general, serum sPSGL-1 concentrations tended to be raised in the early stages of the disease process, but, except in two patients, during the follow up period the values declined to below the initial levels. Thus the serum SPSGL-1 seemed to reflect disease activity. However, as steroids and D-penicillamine were started in 19 of the 35 patients after their first visit, the decrease in SPSGL-1 may have been an effect of these agents. Overall, patients with systemic sclerosis but without pulmonary sclerosis tended to have increased sPSGLl values in the early phase of the disease. In contrast, those with pulmonary sclerosis tended to have decreased SPSGL-1 levels throughout the follow up period.

\section{DISCUSSION}

This is the first report of raised serum SPSGL-1 concentrations in patients with systemic sclerosis. We assessed patients with systemic sclerosis, SLE, and dermatomyositis, but the sPSGL-1 levels were increased only in the patients with

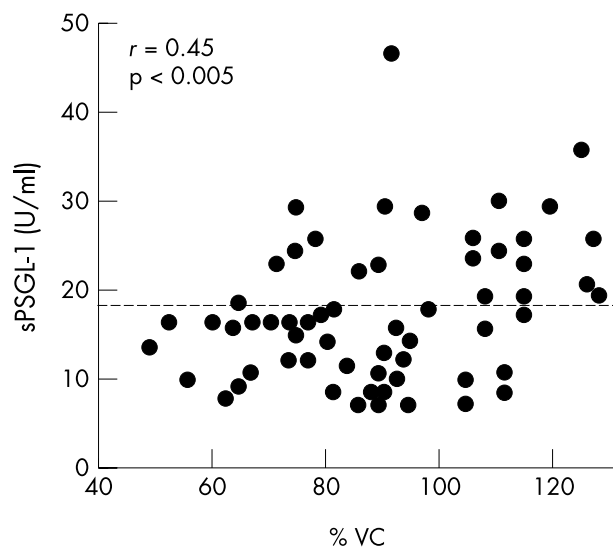

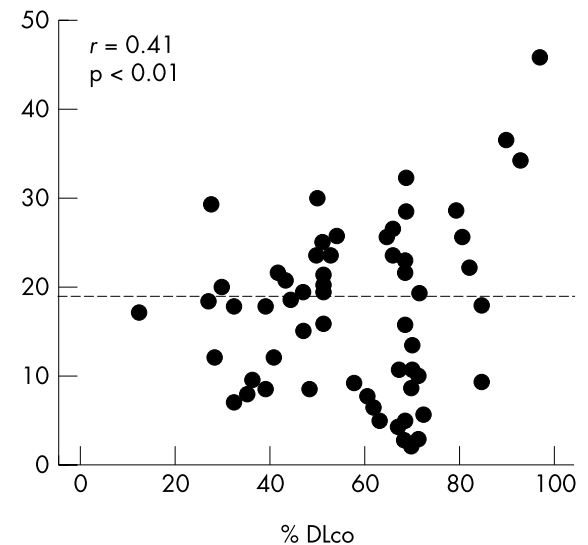

Figure 2 Correlations between serum soluble P-selectin glycoprotein ligand-1 (sPSGL-1) and per cent vital capacity (\%VC) (left) and per cent diffusion capacity for carbon monoxide (\%Dlco) (right) in patients with systemic sclerosis. Serum sPSGL-1 concentrations were determined with a specific enzyme linked immunosorbent assay. The broken lines indicate the cut off value. 

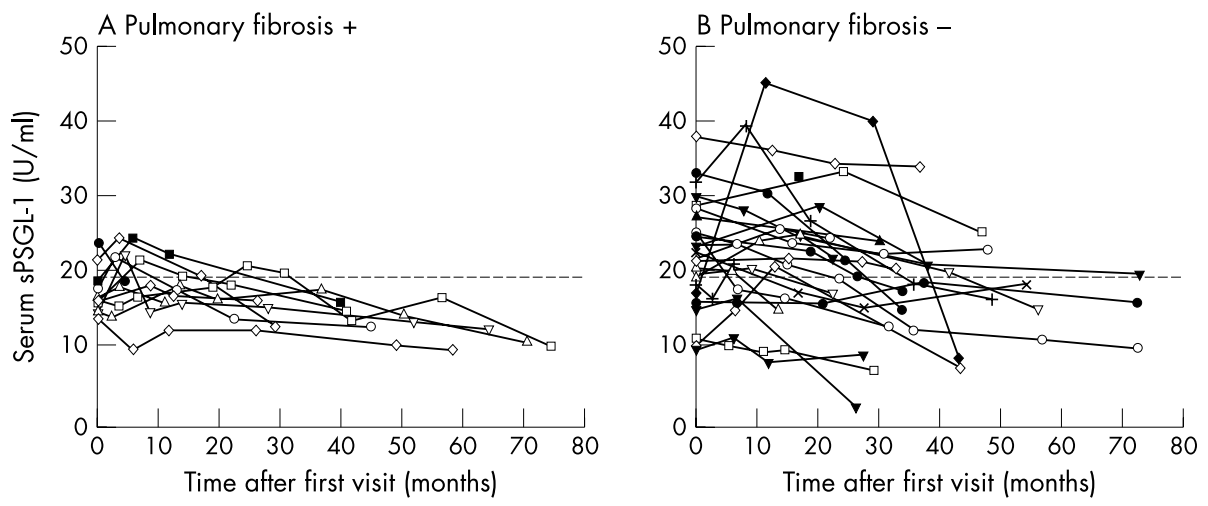

Figure 3 Serial changes in serum soluble P-selectin glycoprotein ligand-1 (sPSGL-1) during the follow up period in patients with systemic sclerosis plus pulmonary sclerosis (A) and without pulmonary sclerosis (B). Serum sPSGL-1 concentrations were determined with a specific enzyme linked immunosorbent assay. Empty symbols represent patients with diffuse cutaneous systemic sclerosis; filled symbols represent patients with limited cutaneous systemic sclerosis. The broken lines indicate the cut off values.

systemic sclerosis (fig 1). The sPSGL-1 concentrations were raised not only in dSSc, but also in ISSc. Furthermore, raised concentrations of SPSGL-1 were associated with a lower prevalence of pulmonary involvement and better pulmonary function (table 1, fig 2). In our longitudinal study, patients with systemic sclerosis but without pulmonary sclerosis tended to have increased sPSGL-1 levels in the early stages of the disease. In contrast, the patients with pulmonary sclerosis tended to have decreased sPSGL-1 levels throughout the follow up period (fig 3 ). Overall, these results suggest that a raised SPSGL-1 may be protective against the development of pulmonary sclerosis in systemic sclerosis.

It has been reported that the soluble forms of various adhesion molecules-including P-selectin, E-selectin, Lselectin, ICAM-1, and VCAM-1-are significantly raised in sera from patients with systemic sclerosis. ${ }^{24-29}$ Raised serum concentrations of SICAM-1, SVCAM-1, and sE-selectin correlate with the severity of skin sclerosis and pulmonary sclerosis in systemic sclerosis. ${ }^{25-27}$ Gruschwitz et al defined clinical disease activity as an increase in skin score, deterioration of pulmonary sclerosis on chest radiograph or PFT, or progression of oesophageal hypomotility shown by barium; and raised serum levels of SICAM-1, VCAM-1, Pselectin, and E-selectin are correlated with clinical disease activity in systemic sclerosis. ${ }^{24}$ Raised serum sL-selectin is linked to a clinically more severe subset of cases of systemic sclerosis. ${ }^{29}$ Furthermore, serum concentrations of sE-selectin, sVCAM-1, and SICAM-1 are raised in cases of systemic sclerosis with scleroderma renal crisis. ${ }^{28}$ Thus the soluble forms of cell adhesion molecules in patients with systemic sclerosis correlate with a more severe type of disease or with major organ involvement, and may reflect disease activity. In this study, sPSGL-1 was also increased in systemic sclerosis. However, the sPSGL-1 values did not correlate with the severity of skin sclerosis, though they did correlate with a lower prevalence of pulmonary sclerosis. These findings suggest that sPSGL-1 may play a specific role in the evolution of systemic sclerosis that is different from the soluble forms of other adhesion molecules such as E-selectin, P-selectin, Lselectin, ICAM-1, and VCAM-1. Moreover, our longitudinal study showed that the patients who did not have pulmonary sclerosis had consistently increased sPSGL-l concentrations in the early phase of disease, whereas those with pulmonary sclerosis had decreased levels throughout the follow up period. These results suggest that measurement of sPSGL-1 in patients with systemic sclerosis may offer an important approach to the evaluation of pulmonary involvement.

Recently, recombinant SPSGL-1 was developed to evaluate the role of P-selectin. ${ }^{10}$ Recombinant sPSGL-1 is engineered by linking a truncated PSGL- 1 to the Fc portion of human immunoglobulin. The protein lacks the transmembrane and cytoplasmic portion of PSGL-1, but contains the complete extracellular regions of PSGL-1 that are necessary for receptor-ligand binding. ${ }^{10}$ It is capable of binding P-, E-, and L-selectins and acts as an antagonist of PSGL- $1 .{ }^{12}{ }^{16}{ }^{17} \mathrm{It}$ has been reported that treatment with recombinant sPSGL-1 is beneficial in animal models of deep vein thrombosis, ${ }^{30}$ myocardial ischaemia-reperfusion, ${ }^{31}{ }^{32}$ renal ischaemiareperfusion, ${ }^{16}$ hepatic ischaemia-reperfusion, ${ }^{33}$ initial hyperplasia after angioplasty, ${ }^{34}{ }^{35}$ arterial thrombosis, ${ }^{36}{ }^{37}$ and ocular allergy.$^{17}$ These previous studies suggest that blocking of leucocyte accumulation through inhibition of the binding of selectins to PSGL-1 provides a means of treating these diseases. In our longitudinal study, the finding that serum sPSGL-1 was raised at the early phase of the disease process in the patients without pulmonary sclerosis (fig 3) suggests that persistent elevation of SPSGL-1 may be related to inhibition of factors concerned with the development of pulmonary sclerosis. Thus the administration of sPSGL-1 might be a possible treatment in patients with systemic sclerosis who have pulmonary sclerosis in the early stages of the disease process.

\section{Authors' affiliations}

K Yanaba, K Takehara, S Sato, Department of Dermatology, Kanazawa University Graduate School of Medical Science, Kanazawa, Japan K Yanaba, Department of Dermatology, Jikei University School of Medicine, Tokyo, Japan

\section{REFERENCES}

1 White B. Immunopathogenesis of systemic sclerosis. Rheum Dis Clin North Am 1996;32:695-708

2 Furst DE, Clements PJ. Hypothesis for the pathogenesis of systemic sclerosis. J Rheumatol 1997;24(suppl 48):53-7.

3 Sato S. Abnormalities of adhesion molecules and chemokines in scleroderma. Curr Opin Rheumatol 1999;11:503-7.

4 Springer TA. Traffic signals on endothelium for lymphocyte recirculation and leukocyte emigration. Annu Rev Physiol 1995;57:827-72.

5 Butcher EC. Leukocyte-endothelial cell recognition: three (or more) steps to specificity and diversity. Cell 1991;67:1033-6.

6 McEver RP. Selectins. Curr Opin Immunol 1994;6:75-84.

7 Tedder TF, Li X, Steeber DA. The selectins and their ligands: adhesion molecules of the vasculature. Adv Mol Cell Biol 1999:28:65-111.

8 Springer TA, Lasky LA. Sticky sugars for selectins. Nature 1991;349:196-7.

9 Patel KD, Moore KL, Nollert MU, McEver RP. Neutrophils use both shared and distinct mechanisms to adhere to selectins under static and flow conditions. J Clin Invest 1995:96:1887-96.

10 Sako D, Chang X-J, Barone KM, Vachino G, White HM, Shaw G, et al. Expression cloning of a functional glycoprotein ligand for P-selectin. Cell 1993;75:1179-86

11 Moore KL, Eaton SF, Lyons DE, Lichenstein HS, Cummings RD, McEver RP. The P-selectin glycoprotein ligand from human neutrophils displays sialylated, 
fucosylated, O-linked poly-N-acetyllactosamine. J Biol Chem 1994;269:22318-27.

12 Sako D, Comess KM, Barone KM, Camphausen RT, Cumming DA, Shaw GD. A sulfated peptide segment at the amino terminus of PSGL-1 is critical for Pselectin binding. Cell 1995:83:323.

13 Asa D, Raycroft L, Ma L, Aeed PA, Kayłes PS, Elhammer AP, et al. The Pselectin glycoprotein ligand functions as a common human leukocyte ligand for P- and E-selectins. J Biol Chem 1995;270:11662-70.

14 Guyer DA, Moore KL, Lynam EB, Schammel CMG, Rogeli S, McEver RP, et al. P-selectin glycoprotein ligand-1 (PSGL-1) is a ligand for L-selectin in neutrophil aggregation. Blood 1996;88:2415-21.

15 Dunlop LC, Skinner MP, Bendall U, Favaloro EJ, Castaldi PA, Gorman JJ, et al. Characterization of GMP-140 (P-selectin) as a circulating plasma protein. $J$ Exp Med 1992;175:1147-50.

16 Takada M, Nadeau KC, Shaw GD, Marquette KA, Tilney NL. The cytokineadhesion molecule cascade in ischemia/reperfusion injury of the rat kidney Inhibition by a soluble P-selectin ligand. J Clin Invest 1997;99:2682-90.

17 Strauss EC, Larson KA, Brenneise I, Foster CS, Larsen GR, Lee NA, et al. Soluble P-selectin glycoprotein ligand 1 inhibits ocular inflammation in a murine model of allergy. Invest Ophthalmol Vis Sci 1999;40:1336-42.

18 Subcommittee for Scleroderma Criteria of the American Rheumatism Association Diagnostic and Therapeutic Criteria Committee. Preliminary criteria for the classification of systemic sclerosis (scleroderma). Arthritis Rheum 1980;23:581-90.

19 LeRoy EC, Krieg T, Black C, Medsger TAJ, Fleischmajer R, Rowell N, et al. Scleroderma (systemic sclerosis): classification, subsets, and pathogenesis. J Rheumatol 1988:15:202-5.

20 Tan EM, Cohen AS, Fries JF, Masi AT, McShane DJ, Rothfield NF, et al. The 1982 revised criteria for the classification of systemic lupus erythematosus. Arthritis Rheum 1982;25:1271-7.

21 Bohan A, Peter JB. Polymyositis and dermatomyositis (first of two parts). N Engl J Med 1975:292:344-8

22 Steen VD, Powell DL, Medsger TAJ. Clinical correlations and prognosis based on serum autoantibodies in patients with systemic sclerosis. Arthritis Rheum 1988;31:196-203.

23 Sato S, Ihn H, Kikuchi K, Takehara K. Antihistone antibodies in systemic sclerosis: association with pulmonary fibrosis. Arthritis Rheum 1994:37:391-4.

24 Gruschwitz MS, Hornstein OP, von Den Driesch P. Correlation of soluble adhesion molecules in the peripheral blood of scleroderma patients with their in situ expression and with disease activity. Arthritis Rheum 1995;38:184-9.
25 Ihn H, Sato S, Fujimoto M, Kikuchi K, Kadono T, Tamaki K, et al. Circulating intercellular adhesion molecule-1 in the sera of patients with systemic sclerosis: enhancement by inflammatory cytokines. Br J Rheumatol 1997;36:1270-5.

26 Ihn H, Sato S, Fujimoto M, Takehara K, Tamaki K. Increased serum levels of soluble vascular cell adhesion molecule-1 and E-selectin in patients with systemic sclerosis. BrJ Rheumatol 1998;37:1 188-92.

27 Denton CP, Bickerstaff MCM, Shiwen X, Carulli MT, Haskard DO, Dubois RM, et al. Serial circulating adhesion molecule levels reflect disease severity in systemic sclerosis. Br J Rheumatol 1995;34:1048-54.

28 Stratton RJ, Coghlan JG, Pearson JD, Burns A, Sweny P, Abraham DJ, et al. Different patterns of endothelial cell activation in renal and pulmonary vascular disease in scleroderma. QJM 1998;91:561-6.

29 Shimada Y, Hasegawa M, Takehara K, Sato S. Elevated serum L-selectin levels and decreased L-selectin expression on CD8(+) lymphocytes in systemic sclerosis. Clin Exp Immunol 2001; 124:474-9.

30 Wakefield TW, Strieter RM, Schaub R, Myers DD, Prince MR, Wrobleski SK, et al. Venous thrombosis prophylaxis by inflammatory inhibition without anticoagulation therapy. J Vasc Surg 2000;31:309-24.

31 Hayward R, Campbell B, Shin YK, Scalia R, Lefer AM. Recombinant soluble Pselectin glycoprotein ligand-1 protects against myocardial ischemic reperfusion injury in cats. Cardiovasc Res 1999;41:65-76.

32 Lefer AM, Campbell B, Scalia R, Lefer DJ. Synergism between platelets and neutrophils in provoking cardiac dysfunction after ischemia and reperfusion: role of selectins. Circulation 1998;98:1322-8.

33 Amersi F, Dulkanchainun T, Nelson SK, Farmer DG, Kato H, Zaky J, et al. A novel iron chelator in combination with a P-selectin antagonist prevents ischemia/reperfusion injury in a rat liver model. Transplantation 2001:71:112-18.

34 Barron MK, Lake RS, Buda AJ, Tenaglia AN. Intimal hyperplasia after balloon injury is attenuated by blocking selectins. Circulation 1997;96:3587-92.

35 Bienvenu JG, Tanguay JF, Theoret JF, Kumar A, Schaub RG, Merhi Y. Recombinant soluble p-selectin glycoprotein ligand-1-lg reduces restenosis through inhibition of platelet-neutrophil adhesion after double angioplasty in swine. Circulation 2001;103:1128-34.

36 Toombs CF, DeGraaf GL, Martin JP, Geng JG, Anderson DC, Shebuski RJ. Pretreatment with a blocking monoclonal antibody to P-selectin accelerates pharmacological thrombolysis in a primate model of arterial thrombosis. $J$ Pharmacol Exp Ther 1995;275:941-9.

37 Kumar A, Villani MP, Patel UK, Keith JC, Schaub RG. Recombinant soluble form of PSGL-1 accelerates thrombolysis and prevents reocclusion in a porcine model. Circulation 1999;99:1363-9. 